\title{
Cross sectional study on arterial hypertension in a general practice setting
}

\author{
Ernesto Mola, ${ }^{1}$ Cristina Melgiovanni ${ }^{2}$ \\ ${ }^{1}$ Associazione Scientifica Interdisciplinare e di Medicina di Famiglia e di Comunità (ASSIMEFAC); ${ }^{2}$ Vocational Training in \\ General Practice, Medical College of Lecce, Italy
}

\begin{abstract}
An observational study on arterial hypertension $(\mathrm{AH})$ in the setting of general practice takes advantages of reaching easily the involved population and of getting information from data recorded in the physicians' databases. Their results could be different from data obtained in specialist settings. The aim of the study is to obtain some prevalence indexes regarding AH and verify if they are consistent with literature. Researchers administered a questionnaire and measured the blood pressure to 478 individuals, randomly selected from the patients' lists

Correspondence: Ernesto Mola, Associazione Scientifica Interdisciplinare e di Medicina di Famiglia e di Comunità (ASSIMEFAC), p.zza Ludovico Ariosto 16, 73100 Lecce, Italy. Tel.: +39.0832.317901.

E-mail: ernestomola.mola@gmail.com

Key words: Arterial hypertension; general practice/family medicine; epidemiology; cross sectional design; heart and circulation.

Acknowledgements: many thanks to the trainees of the Vocational Training in General Practice 2010-2013 of the Medical of 17 general practitioners (GPs). Patients with high value of AH but not acknowledged as hypertensive patients (HP) were invited to come back for two new measurements. Some obtained indexes are not consistent with literature, particularly: i) $97.34 \%$ of the acknowledged hypertensive patients receive a drug treatment; ii) the percentage of HPs not identified by GP is very low (5.05\%); iii) the prevalence of acknowledged HPs at target is higher compared to literature $(64.89 \%)$. The study shows that the knowledge of clinical history of patients recorded by GPs enhances the rigor of the scientific methodology.
\end{abstract} College of Lecce, who carried out this study and contributed to design the protocol and the questionnaire: Francesco Briatico, Valentina Buonuomo, Gianfranco Cesi, Lucia Ciampo, Maria Odette Coppola, Marco Corsano, Antonio Labate, Raffaele Ligori, Maria Luisa Mariano, Chiara Palma. Thanks also to Rino Serra and Claudia Felici, who contributed to draw up the protocol, and to trainers Family Doctors: Anguilla G, Cazzato D, Dimo E, Fiume D, Fusco D, Girasoli A, Greco M, Gualtieri L, Macchia C, Marati A, Massa L, Monte F, Paglialunga C, Rizzo R, Saracino I, Serra C, Tosi F.

Funding: the work was supported by the Medical College of the Province of Lecce.

Contributions: the authors contributed equally. The first author coordinated the research.

Conflict of interests: the authors declare no potential conflict of interest.

Conference presentations: this work was presented at the $19^{\text {th }}$ European Conference of WONCA, 2013 July 2-5, Lisbon, Portugal and at the $31^{\text {th }}$ Conference of SIIA, 2014 October 9-11, Bologna, Italy.

Received for publication: 30 January 2015.

Revision received: 26 February 2015.

Accepted for publication: 27 February 2015.

This work is licensed under a Creative Commons Attribution NonCommercial 4.0 License (CC BY-NC 4.0).

CCopyright E. Mola and C. Melgiovanni, 2016 Licensee PAGEPress, Italy

Italian Journal of Medicine 2016; 10:128-133

doi:10.4081/itjm.2016.581

\section{Introduction}

The Guidelines for management of arterial hypertension of European Society of Hypertension (ESH) European Society of Cardiology (ESC) consider 140/90 mmHg as the initial value of Grade 1 of hypertension. ${ }^{1}$ Overall, the prevalence of arterial hypertension (AH) appears to be around $30-45 \%$ of general population.

Evidence from randomized controlled trials has shown that the reduction in blood pressure (BP) in patients with $\mathrm{AH}$ is beneficial in preventing cardio-vascular diseases and mortality. ${ }^{2}$ Nevertheless, high percentages of individuals with $\mathrm{BP} \geq 140 / 90$ are unaware of their condition of hypertensive patients (HP) and not treated. In the ' 70 s this percentage was estimated about $65 \%$, but recently it has been calculated about $50 \%{ }^{3,4}$

Patients with $\mathrm{AH}$ as unique risk factor, and with cardio-vascular risk (CVR) - according to the SCORE CHART - less than $5 \%$ in young people and $10 \%$ in elderly people, should not be treated with drugs for several months, but only with behavioral changes. ${ }^{5}$ This recommendation has been confirmed in the cited ESH-ESC 2013 guidelines.

In Italy, the most recent data from Epidemiologic Cardiovascular Observatory (OEC) of the Institute of 
Health point out that more than $50 \%$ of men and more than $40 \%$ of women between $35-79$ years have a BP $\geq 140 / 90$. In the male population, BP is higher than in female population on average. $43 \%$ of men are not taking any drug treatment, while women not treated are $33 \%$. In South and Islands, treated hypertensive patients are more than in the other Italian regions: $64 \%$ of men and $73 \%$ of women. ${ }^{6}$ In 2008 , prevalence of patients at target was $37.93 \%$ for men and $42.30 \%$ for women. Data of OEC have been exclusively obtained in hospitals.

Currently, most studies concerning arterial hypertension and surveys of prevalence indexes are carried out in specialist settings, and are usually based on a unique consultation for BP measurement and for registration of anamnestic data. In Italy, only a retrospective study was carried out in a general practice setting. It was based on data of HPs recorded in the database of 21 voluntary GPs without randomization, and aimed to evaluate mainly the effectiveness of treatments. ${ }^{7}$

\section{Possible advantages of the general practice/primary care setting}

General practice is a favourable setting for validity and originality of an observational study on AH. Particularly: i) it provides easy access to the involved population because in Italy, like in several countries, all citizens are recorded in the GPs' patient lists; ii) it benefits from the strong relationship between patients and doctors based on trust, which determines a low drop-out; iii) it allows to obtain a BP measurement in the habitual conditions of the GP's office, which probably reduces the white coat hypertension; iv) it allows to easily correlate the measurement obtained in office with the home blood pressure monitoring (HBPM); v) GPs are in possession of anamnestic data concerning the condition of HP (if patient is acknowledged as HP, drug treatment, etc.), which are usually recorded in an electronic medical record system (EMRS).

The authors of this study had realized that data of hypertensive patients obtained from their EMRS were different from scientific literature; in particular, those concerning the percentage of HPs treated with drugs, of patients at target, and of HPs unaware of their condition.

The hypothesis at the basis of this study is that an observational study on AH carried out in the setting of GP could give different results compared to scientific literature.

\section{The compliance issue}

Regarding chronic conditions, scientific literature shows that patient compliance with medication is less than $50 \%,{ }^{8}$ and that adherence rates to lifestyle changes are less than $10 \% .{ }^{9}$ Sometimes the failure to achieve the BP target has been imputed to under-treatment. Recently the term therapeutic inertia has been coined to define the resistance and laziness of doctors in modifying drug treatments. ${ }^{10}$ This study wants to investigate the extent to which each item influences the missed achievement of the BP target.

\begin{abstract}
Aims
The study is aimed: i) to obtain some prevalence indexes regarding $\mathrm{AH}$ with an observational study in a setting of GP, and verify if they are consistent with literature; ii) to obtain a percentage of hypertensive patients with $\mathrm{AH}$ of grade 1 as unique risk factor, with a CVR index less than 5\% in young people and $10 \%$ in elderly people, who are receiving drug treatment; iii) to measure some determinants concerning the not achievement of the BP target.
\end{abstract}

\section{Materials and Methods}

Among the training activities, the Italian Vocational Training of General Practice includes knowledge concerning research in general practice. The trainees of the Vocational Training 2010-2013 held by the Medical College of Lecce carried out this study in their area. They contributed also to draw up of the protocol and the questionnaire.

After defining a sample size of 369 patients - expected prevalence $40 \%$, absolute accuracy 0.05 , and confidence interval $95 \%$ - each trainee recruited about thirty patients, men and women, extracted randomly from the EMRS of each of seventeen GPs.

After signing an informed consent form, patients were interviewed about physiologic and pathologic anamnesis, and the information from patients was matched with data of EMRS.

Then the researchers measured BP, according to the international guidelines' methodology. Particularly $\mathrm{BP}$ was measured after five minutes of rest and two times again, at intervals of two minutes.

If a patient showed high values of BP after the third measurement and he/she was already acknowledged as HP or treated with anti-hypertensive drug, the researcher concluded the interview with a few questions about drug taking, including the short questionnaire of Morisky concerning adherence to treatment.

If a patient with high values of BP was not acknowledged as HP - either from anamnesis or from data of EMRS - he/she was invited to come two times again for new measurements after two and four weeks.

If a patient showed high values of BP at the third meeting, the researcher concluded the interview with few questions aimed to understand why he/she was not acknowledged as HP. 


\section{Results}

\section{Population of the study}

The eleven students of the vocational training recruited 535 patients, from 25 to 75 years old, extracted randomly from the EMRS of seventeen general practitioners of the province of Lecce - South of Italy, 801,000 inhabitants. 57 patients $(10.65 \%)$ dropped out and 478 completed the research: 236 men, 242 women, mean age 54 years (standard deviation 13).

\section{General indexes}

Some main findings are in Table 1.

While the mean value of BP, the correlation indexes Age/BP, and the prevalence of HPs are in line with general statistics, the percentages of acknowledged HPs (94.95\%) and acknowledged HPs treated $(97.34 \%)$ are very high, compared with the majority of Italian and international studies, with no significant differences between the two sexes.

The 188 hypertensive patients were asked if they thought they were carriers of arterial hypertension, and 17 replied in the negative. That means that $9.04 \%$ of
HPs of our sample were unaware of their chronic condition, even though in the EMRS of the general practitioners the hypertensive condition or the anti-hypertensive treatment were clearly recorded.

\section{Acknowledged hypertensive patients}

The percentage of acknowledged HPs at target $(64.89 \%)$ is higher than in most studies, with a greater value for women. In Italy data of OEC of 2008 show a percentage of patients at target of about $40 \%$ of treated HPs. ${ }^{6}$

From EMRS it was possible to verify that, at the moment of the first diagnosis, most HPs had shown arterial hypertension of grade 1 - the $58.15 \%$ with systolic blood pressure (SBP) between 140 and 159 and the $62.16 \%$ with diastolic blood pressure (DBP) between 90 and 99), while $35.87 \%$ had shown SBP $\geq 160$, and $28.65 \%$ DBP $\geq 100$.

While the ESH-ESC guidelines suggest avoiding treatment with drug for long time in patients with Grade 1 hypertension and low CVR $(<5 \%$ in young and $<10 \%$ in elderly patients), we found that $93.94 \%$ of them under 65 , and $100 \%$ over 65 were taking antihypertensive drugs.

Table 1. The main prevalence indexes.

\begin{tabular}{|c|c|c|}
\hline & Absolute numbers & $\%$ \\
\hline \multirow[t]{3}{*}{ Average of BP measurements in all the recruited patients } & $\begin{array}{l}\text { In all: } \\
\text { SBP } 127(\mathrm{SD}=14) \\
\text { DBP } 79(\mathrm{SD}=8)\end{array}$ & \\
\hline & $\begin{array}{l}\text { Men: } \\
\text { SBP } 130 \\
\text { DBP } 81\end{array}$ & \\
\hline & $\begin{array}{l}\text { Women: } \\
\text { SBP } 123 \\
\text { DBP } 77\end{array}$ & \\
\hline Correlation index: age/SBP & 0.36 & \\
\hline Correlation index: age/DBP & 0.15 & \\
\hline Hypertensive patients & $\begin{array}{l}\text { In all: } 198 \\
\text { Men: } 121 \\
\text { Women: } 77\end{array}$ & $\begin{array}{l}41.42 \\
48.7 \\
30.17\end{array}$ \\
\hline Acknowledged HPs (from 8.9 years on average) & $\begin{array}{l}\text { In all: } 188 \\
\text { Men: } 115 \\
\text { Women: } 73\end{array}$ & $\begin{array}{l}94.95 \text { of all HPs } \\
95.04 \\
94.81\end{array}$ \\
\hline HPs treated with drugs & $\begin{array}{l}\text { In all: } 183 \\
\text { Men: } 112 \\
\text { Women: } 71\end{array}$ & $\begin{array}{l}97.34 \text { of acknowledged HP } \\
97.39 \\
97.26\end{array}$ \\
\hline HPs at target (according to the ESH-ESC 2013 guidelines) & $\begin{array}{l}\text { In all: } 122 \\
\text { Men: } 70 \\
\text { Women: } 52\end{array}$ & $\begin{array}{l}64.89 \text { of acknowledged HPs } \\
60.87 \\
71.23\end{array}$ \\
\hline Not acknowledged as HPs & $\begin{array}{l}\text { In all: } 10 \\
\text { Men: } 6 \\
\text { Women: } 4\end{array}$ & $\begin{array}{l}5.05 \text { of all HPs } \\
4.96 \\
5.19\end{array}$ \\
\hline
\end{tabular}

SBP, systolic blood pressure; DBP, dyastolic blood pressure; SD, standard deviation; HP, hypertensive patients; ESH-ESC, European Society of Hypertension-European Society of Cardiology. 
HBPM brings advantages regarding the achievement of the BP target ( $66.67 \%$ versus $61.97 \%)$, but if patients measure the BP weekly or daily, the percentages of patients at target rise respectively to $73.08 \%$ and to $75.00 \%$.

\section{Treatment}

Figure 1 shows the classes of drug taken by the 183 treated HPs of the sample.

The most used drug are angiotensin II receptor blockers (ARBs) (40.98\%) and $\beta$-blockers (39.34\%), but all classes of anti-hypertensive are well represented. ARBs, angiotensin-converting enzyme inhibitors and $\beta$-blockers are used in monotherapy as well as in combination, while diuretics and $\mathrm{Ca}$-antagonist are used mainly in combination. Then these two classes of drugs are hardly ever prescribed at the start of treatment. Altogether $40.98 \%$ of patients take a monotherapy.

\section{Hypertensive patients not at target}

See in Table 2 the data regarding acknowledged HPs not at target.

They show mainly an increased SBP. GPs were asked to say if they consider their HPs at target. Results showed that $58.21 \%$ of HPs not at target are considered by GPs achieving the therapeutic goal. This could be at the basis of the therapeutic inertia.

The EMRS of GPs showed that 14 out of 67 HPs not at target $(20.90 \%)$ had had at least one prescription of an anti-hypertensive drug, which they were not taking. In these cases the failure to achieve the BP target would be imputable to a low adherence to the prescriptions.

Researchers administered to the HPs not at target also the short questionnaire of Morisky. It is a validated questionnaire of four questions aimed to measure the adherence to the ongoing drug treatment. The score is from zero to four and a higher value shows a

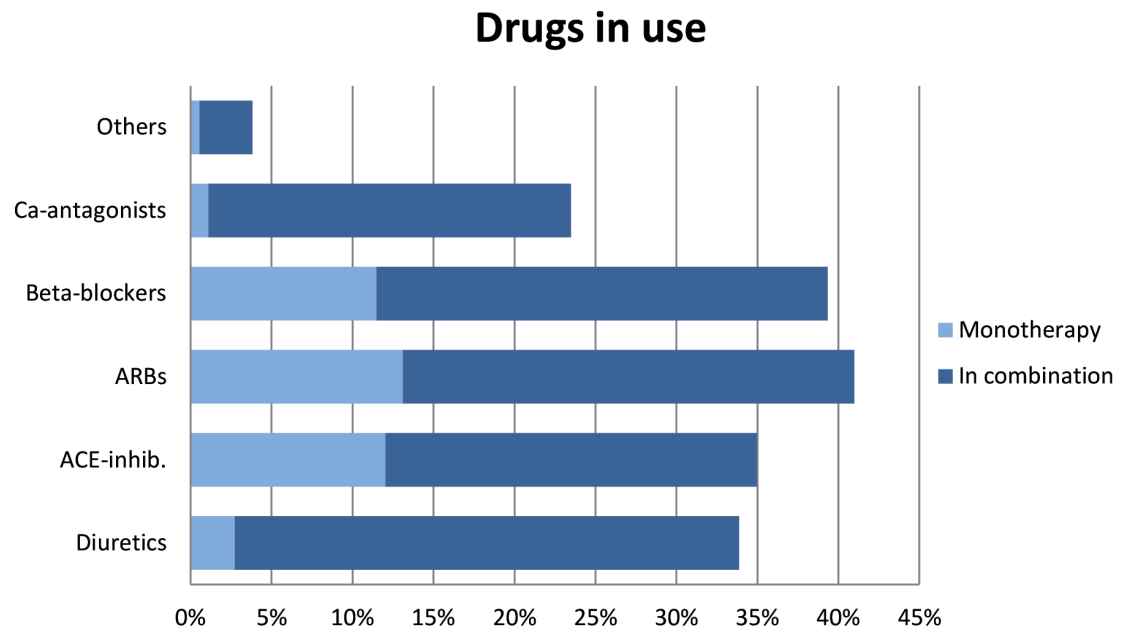

Figure 1. Classes of drug used by hypertensive patients of the sample. ARBs, angiotensin II receptor blockers; ACEinib., angiotensin-converting enzyme inhibitors.

Table 2. Hypertensive patients not at target considered by their general practitioners at target.

\begin{tabular}{lcccc}
\hline \multicolumn{2}{c}{ HPs not at target } & \multicolumn{2}{c}{ GPs consider at target } \\
\hline$\geq 140$ & 50 & $26.46 \%$ & 28 & $41.79 \%$ \\
\hline$\geq 0$ & 39 & $20.63 \%$ & 24 & $35.82 \%$ \\
\hline$\geq 140 \geq 90$ & 23 & $12.23 \%$ & 13 & $19.40 \%$ \\
\hline$\geq 140<90$ & 27 & $14.36 \%$ & 15 & $22.39 \%$ \\
\hline$<140 \geq 90$ & 17 & $9.04 \%$ & 11 & $16.42 \%$ \\
\hline Total & 67 & $35.64 \%$ & 39 & $58.21 \%$ \\
\hline
\end{tabular}

HP, hypertensive patients; GPs, general practitioners. 
better adherence to treatment. ${ }^{11}$ The mean value of Morisky's score of patients not at target is 2.63. Only few patients show a very low adherence, while the $54.84 \%$ shows a good adherence because they reach the value 3 or 4 . These patients, with good adherence but not at target, should be therefore considered undertreated (Figure 2).

An interesting result regards the use of nonsteroidal anti-inflammatory drugs (NSAIDs) and cortisone. Twenty-one out of 96 patients $(21.88 \%)$ who showed at the first measurement SBP $\geq 140$ or $\geq 90$ had taken NSAIDs in the previous 48-h, and seven $(7.29 \%)$ cortisone. The high incidence of these events would suggest including in the routine anamnesis of patients, who show high value of BP, the recent use of these drugs.

\section{Not acknowledged hypertensive patients}

In this study, they are ten at the third measurement, $5.05 \%$ of all HPs, while patients not acknowledged as HPs who had shown high level of BP at the first measurement were thirty. The difference between the measurements could be partly imputable to a white coat hypertension.

It is not possible to make statistical analysis in such small group of patients. A few data concerning not acknowledged HPs are in Figure 3.

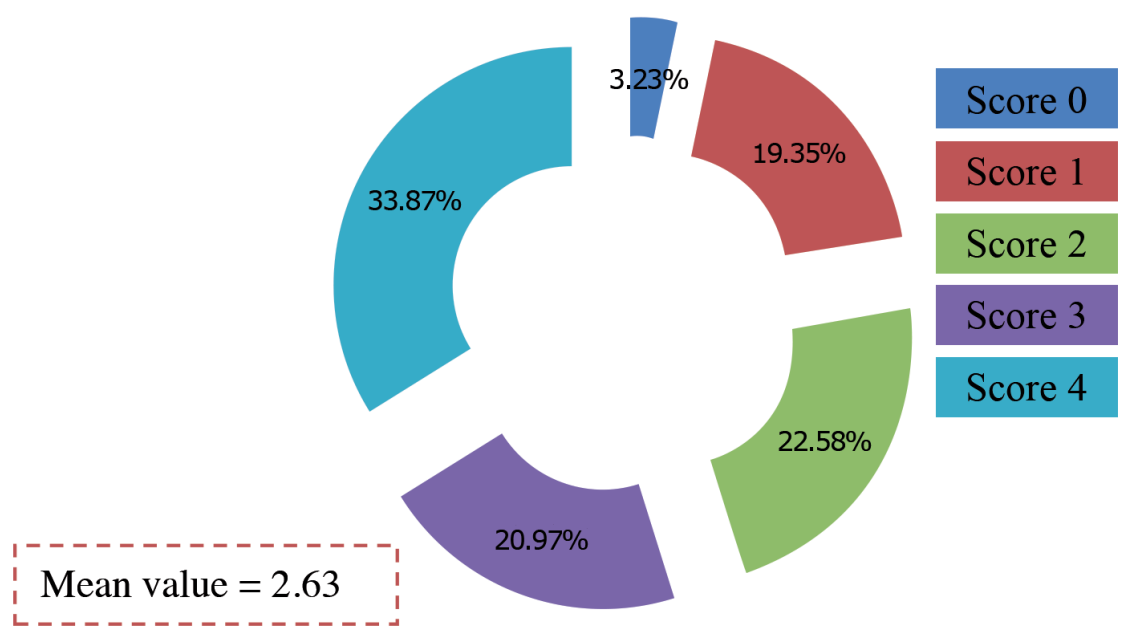

Figura 2. Questionnaire of Morisky administered to hypertensive patients not at target. A higher score shows a better adherence.

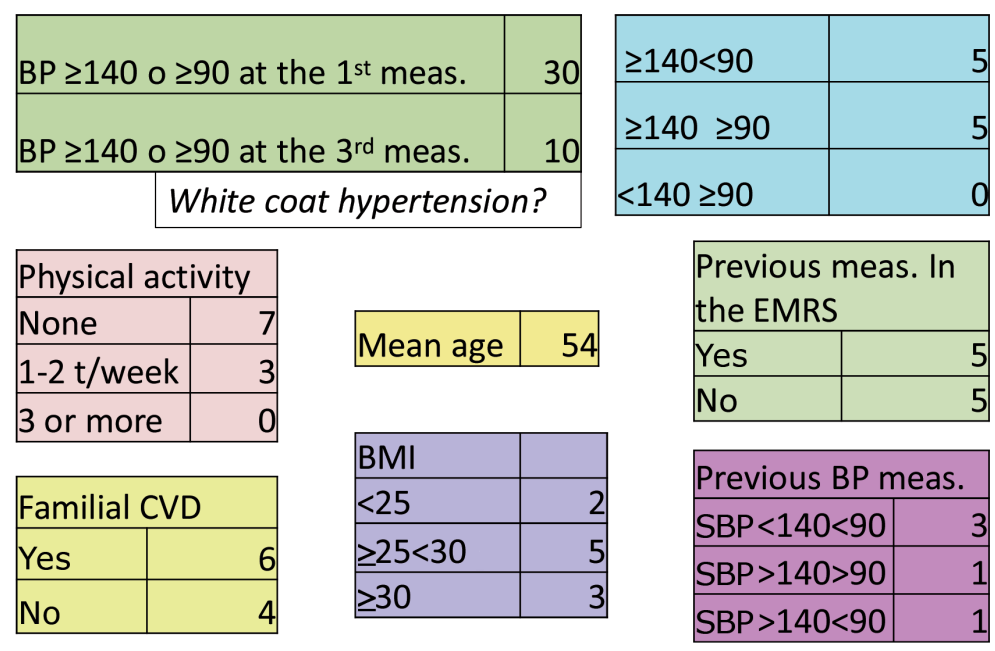

Figura 3. A few data concerning not acknowledged hypertensive patients (HPs). BP, blood pressure; EMRS, electronic medical record system; CVD, cardio-vascular disease; BMI, body mass index; SBP, systolic blood pressure. 
It shows poor physical activity, body mass index at the highest levels, and high number of familial cardio-vascular diseases. For five of them, at least one previous measurement of $\mathrm{BP}$ had been recorded in the EMRS, and three had shown a normal value.

\section{Discussion}

Some prevalence indexes are consistent with literature, but other data of the randomized sample of the study are very different.

Particularly: i) nearly all the acknowledged HPs receive a drug treatment, even patients who had had at diagnosis SBP between 140 and 159, DPB between 90 and 99, and low CVR; ii) the prevalence of not acknowledged HPs is lower than that of the studies carried out in specialist settings; iii) the prevalence of patients at target is higher than that in most studies; iv) 9.04\% of acknowledged HPs were unaware of their chronic condition; v) the failure to achieve the therapeutic goal is attributable to several measurable factors which may act simultaneously: low adherence (21\%); under-treatment (54\%); therapeutic inertia (58\%).

All classes of drugs are used, but diuretics and caantagonists are not generally used in monotherapy.

\section{Conclusions}

The apparently surprising results regarding the high percentage of treated patients and of patients at target lie in the opportunity to obtain anamnestic data based on the recorded clinical history of each patient, and to have a BP measurement in habitual conditions.

The study shows the feasibility and the originality of a cross sectional study on arterial hypertension carried out in the setting of general practice. In fact, it is possible to match information reported by the recruited patients with data recorded in the EMRS of doctors, which represents a huge source of clinical news concerning anamnesis, drug treatment, previous measurements and tests. Besides, patient is accustomed to come to the office of GP and usually accepts gladly to be collaborative.

Furthermore, it seems possible to better investigate and try to measure some determinants concerning the failure to achieve the BP target.

In conclusion, the rigor of the scientific method- ology can go well with - and can be enhanced by - the knowledge of the clinical history of patients recorded in the EMRSs of GPs.

\section{References}

1. Mancia G, Fagard R, Narkiewicz K, et al. 2013 ESH/ESC Guidelines for the management of arterial hypertension: the Task Force for the management of arterial hypertension of the European Society of Hypertension (ESH) and of the European Society of Cardiology (ESC). J Hypertens 2013;31:1281-357.

2. Mac Mahon S, Peto R, Cutler J, et al. Blood pressure, stroke and coronary heart disease. Lancet 1990;335: 765-74

3. Giampaoli S, Vanuzzo D. [Cardiovascular risk factors in Italy: an interpretation with reference to th National Health Plan 1998-2000. Research Group of the Cardiovascular Epidemiologic Observatory]. G Ital Cardiol 1999;29:1463-71. [Article in Italian]

4. Chow CK, Teo KK, Rangarajan S, et al. Prevalence, awareness, treatment, and control of hypertension in rural and urban communities in high-, middle-, and lowincome countries. JAMA 2013;310:959-68.

5. Graham I, Atar D, Borch-Johnsen K, et al. European guidelines on cardiovascular disease prevention in clinical practice: full text. Fourth Joint Task Force of the European Society of Cardiology and other societies on cardiovascular disease prevention in clinical practice (constituted by representatives of nine societies and by invited experts). Eur J Cardiovasc Prev Rehabil 2007;14:S1-113.

6. Palmieri L, Donfrancesco C, Vannucchi S, et al. Ipertensione: i dati dell'osservatorio epidemiologico cardiovascolare/health examination survey. Available from: http://www.epicentro.iss.it/approfondimenti/2013/whdDatiOEC.asp Accessed: January 2014.

7. Degli Esposti E, Di Martino M, Sturani A, et al. Risk factor for uncontrolled hypertension in Italy. J Hum Hypertens 2004;18:207-13.

8. World Health Organization (WHO). Adherence to longterm therapies - evidence for action; 2003. Available from: http://whqlibdoc.who.int/publications/2003/9241 545992.pdf

9. Haynes RB, McDonald HP, Garg AX, Helping patients follow prescribed treatment: clinical application. JAMA 2002;288:2880-3.

10. Nesbitt SD. Overcoming therapeutic inertia in patients with hypertension. Postgrad Med. 2010;122:118-24.

11. Morisky DE, Green LW, Levine DM, Concurrent and predictive validity of self reported measure of medication adherence. Med Care 1986;24:67-74. 